\title{
TRISOMY 18: REFERRALS TO A CHILDREN'S PALLIATIVE CARE SERVICE
}

B. Hannon ${ }^{1}$, V. Jennings ${ }^{2}$, E.J. Nolloy ${ }^{3,4}$, M. Twomey ${ }^{2}$, M. O'Reilly ${ }^{2}$

${ }^{1}$ Department of Palliative Medicine, St Vincent's University Hospital, ${ }^{2}$ Department of Palliative Medicine, Our Lady's Childrens Hospital, Crumlin, Dublin 12, ${ }^{3}$ Department of Neonatology, Our Lady's Childrens Hospital, Crumlin, ${ }^{4}$ Department of Neonatology, National Maternity Hospital, Dublin, Ireland

Background: Trisomy 18 is the second most common autosomal trisomy in liveborn infants, characterised by severe psychomotor and growth retardation.

The median survival is 19 days, with only $5-8 \%$ surviving their first year of life. Despite recognising that trisomy 18 is almost invariably associated with death in infancy or early childhood, there is a dearth of published data regarding the palliative care needs of these patients.

It is estimated that there are $20-25$ new cases of trisomy 18 in Ireland annually, although the lack of a national database makes it difficult to confirm incidence rates.

Aims: To assess the referral rate of trisomy 18 to a Palliative Care service, review symptom burden and outcomes in terms of life expectancy \& place of death.

Methods: A retrospective chart review of all cases referred over a ten-year period (2001-2010).

Results: 20 referrals were made. All had classical physical characteristics of trisomy 18 . The most common reasons for referral were feeding $\&$ breathing difficulties, irritability and assistance with discharge planning. Mean age at death was 64 days.

Discussion: This is the first study to review the specific palliative care needs of infants born with trisomy 18 , to show that successful home discharge is possible \& to comment on place of death.

A national database is needed to identify infants diagnosed with trisomy 18 , \& to ensure correct resource allocation.

Neonatal pathways for babies with trisomy 18 could provide a framework for decision making \& care planning, from diagnosis to bereavement support. 